\section{Cholestasis secondary to hyperthyroidism in Graves' disease. Report of one case}

\author{
MARÍA I. BARRA ${ }^{1}$, ROBERTO OLMOS ${ }^{2}$, \\ FRANCISCO BARRERA ${ }^{3}$, LORENA MOSSO ${ }^{2}$, \\ JOSÉ M. DOMÍNGUEZ ${ }^{2}$
}

\section{ABSTRACT}

Hyperthyroidism can induce elevation in several liver function tests including aminotransferases, alkaline phosphatases and, less frequently, serum bilirubin. These alterations are usually mild and asymptomatic. We report a 26 year-old male presenting with palpitations, progressive jaundice, choluria and generalized itching. Laboratory tests were compatible with hyperthyroidism and a mild elevation of bilirubin, alkaline phosphatases and gamma glutamyl transpeptidase. A liver biopsy showed portal hepatitis with canalicular cholestasis. The patient was treated temporarily with glucocorticoids, cholestyramine and betablockade. Thereafter, he was treated with radioactive iodine, after which serum bilirubin decreased steadily until normalization in ten weeks.

(Rev Med Chile 2020; 148: 697-701)

Key words: Graves Disease; Hyperbilirubinemia; Hyperthyroidism.

\section{Colestasia en un paciente con hipertiroidismo por enfermedad de Graves. Informe de un caso}

El hipertiroidismo puede producir elevación de aminotransferasas, fosfatasas alcalinas $y$, menos frecuentemente, de bilirrubina sérica. Habitualmente, estas alteraciones son leves y asintomáticas. Reportamos un hombre de 26 años con hipertiroidismo secundario a enfermedad de Basedow-Graves, que debutó con un cuadro colestásico, inicialmente estudiado por sospecha de patología hepática autoinmune que incluyó biopsia hepática. Posteriormente, se diagnosticó hipertiroidismo que fue tratado con glucocorticoides, colestiramina y beta bloqueo como puente a terapia definitiva con radioyodo. La evolución mostró disminución progresiva hasta la normalización de bilirrubina sérica.

Palabras clave: Enfermedad de Graves; Hiperbilirrubinemia; Hipertiroidismo.

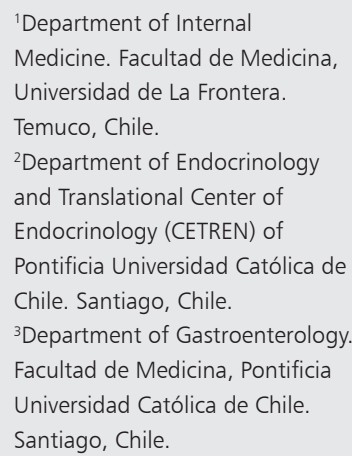

Disclosure: the authors have nothing to disclose.

No potential conflict of interest relevant to this article was reported.

Recibido el 30 de septiembre de 2019, aceptado el 27 de abril de 2020.

Corresponding Author: José Miguel Domínguez Departaments of Endocrinology, Pontificia Universidad Católica de Chile.

Diagonal Paraguay 362, Santiago Chile.

jdomingu@uc.cl
$\mathrm{H}$ yperthyroidism is a clinical syndrome derived from the exposure of tissues to an excess of thyroid hormones, with a generalized acceleration in all metabolic processes. Between 45 and $90 \%$ of hyperthyroid patients develop altered liver function tests, which are usually mild and asymptomatic ${ }^{1}$. However, there have been case reports of acute hepatitis, acute liver failure and acute cholestasis ${ }^{1,2}$. In 1874, Habershon published the first case of liver failure secondary to hyperthyroidism ${ }^{3}$. Since then, only eight cases of hyperthyroidism associated to a severe cholestatic 
Table 1. Liver functions tests at diagnosis and during follow-up after radioactive iodine ablation

\begin{tabular}{|lcccccc|}
\hline & Day 1 & Day 7 & Day 20 & Day 30 & $\begin{array}{c}\text { Week 10 } \\
\text { post RAl }\end{array}$ & $\begin{array}{c}\text { Year 1 } \\
\text { post RAl }\end{array}$ \\
\hline T Bili/D $(<1.0 /<0.3 \mathrm{mg} / \mathrm{dl})$ & $3.88 / 2.94$ & $5.46 / 4.4$ & $11.17 / 9.24$ & $15.3 / 13.7$ & $0.9 / 0.42$ & $0.37 / 0.18$ \\
AST $(10-40 \mathrm{U} / \mathrm{L})$ & 172 & 163 & 108 & 25 & 21 & 15 \\
ALT $(10-55 \mathrm{U} / \mathrm{L})$ & 223 & 318 & 208 & 71 & 45 & 23 \\
GGT $(<60 \mathrm{U} / \mathrm{L})$ & 52 & 42 & 24 & 18 & 15 & 12 \\
FA (45-115 U/L) & 148 & 141 & 184 & 171 & 113 & 95 \\
INR (0.9-1.15) & 1.1 & 1.2 & 1.2 & & & \\
\hline
\end{tabular}

T BILI = Total bilirubin/direct; AST: Aspartate aminotransferase; ALT: Alanine aminotransferase; GGT: Gamma glutamyl transpeptidase; FA: Alkaline phosphatase; INR: International Normalized Ratio; RAI = Radioactive iodine.

syndrome have been reported in the literature.

Many hypotheses have been proposed to explain the abnormalities in liver function tests, including relative liver hypoxia, cardiac insufficiency with liver venous congestion, direct damage induced by excess triiodothyronine (T3) or anti-TSH receptor antibodies (TRAb), co-existence of autoimmune liver disease, and antithyroid drug-induced hepatotoxicity ${ }^{1,3-5}$. Diagnosis and management of this clinical scenario is challenging because thionamides are usually withheld, because of concerns regarding aggravating liver toxicity ${ }^{3}$.

We report the case of a patient with hyperthyroidism secondary to Graves' disease that presented with jaundice and progressive itching. He was successfully managed with glucocorticoids, cholestyramine and propranolol, until administration of radioactive iodine, followed by resolution of hyperthyroidism and liver function abnormalities.

\section{Case}

A twenty-six-year-old male presented to a gastroenterologist after six months of malaise and $15 \mathrm{~kg}$ weight loss, followed the last month by palpitations, progressive jaundice, choluria and generalized itching. History was negative for risk factors for infectious hepatitis (travels, blood transfusions, tattoos, piercings, use of intravenous drugs and high-risk sexual behavior) as well as known hepatotoxic drugs or homeopathic products. On physical examination he was alert, with a body mass index of $18.5 \mathrm{~kg} / \mathrm{m}^{2}$. His blood pressure was $120 / 80 \mathrm{mmHg}$, with a regular heart rate of 85 bpm. He had profound jaundice of sclerae and skin, with no abdominal findings.

Initial biochemical workup showed four-fold elevation in aminotransferases and direct bilirubin, with mild elevations in gamma glutamyl transpeptidase (GGT) and alkaline phosphatases (AP) (Table 1). Workup for infectious and autoimmune causes of hepatitis was negative (Table 2). Abdominal computed tomography showed mild splenomegaly and magnetic resonance (MR) cholangiogram was negative for cholelithiasis and choledocholithiasis. The patient was initially managed with ursodeoxycholic acid $750 \mathrm{mg} /$ day, cholestyramine $2 \mathrm{~g}$ tid and hydroxyzine. After one week with worsening of bilirubin concentration up

Table 2. Panel of autoimmune and viral causes of liver failure

\begin{tabular}{|ll|}
\hline Test & Result \\
\hline Hepatitis A virus IgM & Negative \\
Hepatitis E virus IgM & Negative \\
Hepatitis B virus (HBsAg) & Negative \\
Hepatitis C virus (anti- HCV) & Negative \\
\hline IgM CMV & Negative \\
\hline Toxoplasma IgM & Negative \\
Epstein Barr IgG & Negative \\
Mononucleosis (anti-heterophile antibodies) & Negative \\
Antinuclear antibodies (ANA) & Negative \\
Anti-smooth muscle antibodies (ASMA) & Negative \\
Anti-mitochondrial antibodies (AMA) & Negative \\
Anti-endomysial antibodies (EMA) & Negative \\
\hline
\end{tabular}




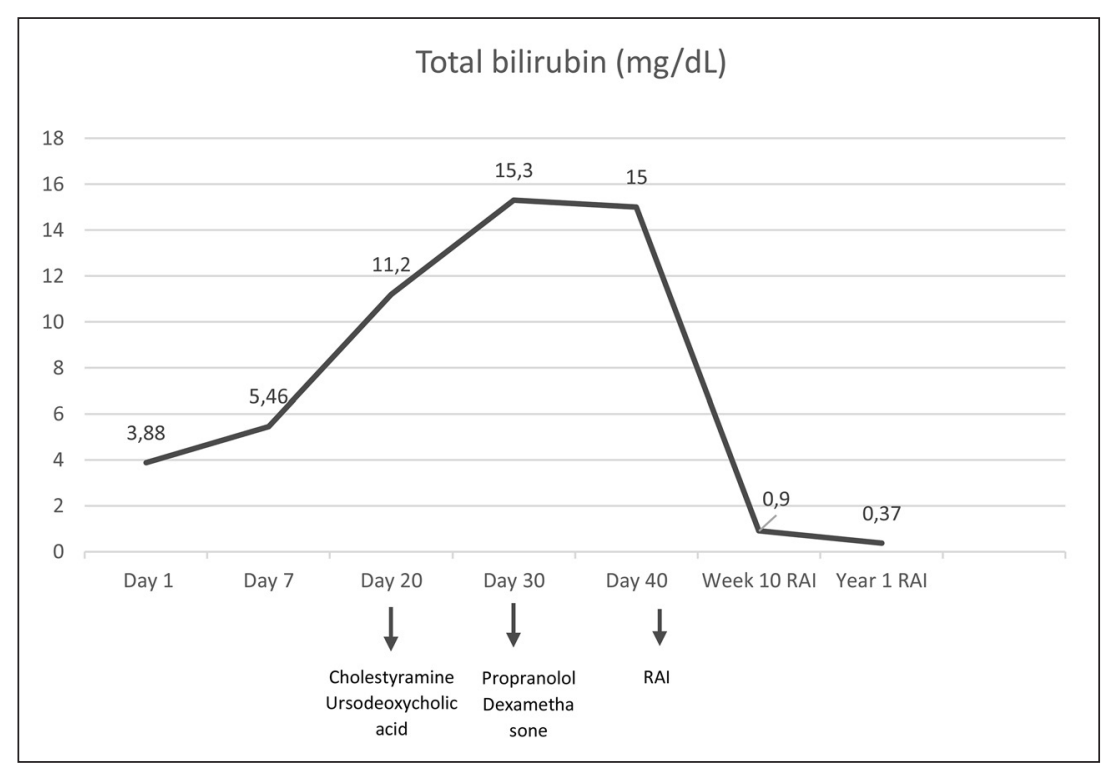

Figure 1. RAl: radioactive iodine. to $15 \mathrm{mg} / \mathrm{dL}$, a liver biopsy was performed. During hospitalization the patient developed progressive sinus tachycardia up to $130 \mathrm{bpm}$ and tremor of extremities. Re-interrogation of symptoms was notable for at least 6 months of palpitations, frequent bowel movements without diarrhea and muscle weakness. The patient denied use of thyroid hormone, ocular symptoms, fever or neck tenderness. Physical examination was notable for fine hand tremor, warm skin and positive Graefe's sign, without goiter, signs of orbitopathy or pretibial myxedema.

Thyroid function tests were notable for TSH: $<0.005 \mathrm{uUI} / \mathrm{ml}(0.3-4.2 \mathrm{uUI} / \mathrm{ml})$, FT4: $>7.77$ mcg/dL (0.93-1.7), T3: 567.8 ng/dl (84.6-201.8) and TRAb: $25.7 \mathrm{UI} / \mathrm{L}$ (normal $<1.75 \mathrm{UI} / \mathrm{L}$ ). Thyroid ultrasound showed a small diffuse goiter with enhanced vascularization. The diagnosis of Graves' disease was made and, given the fact that antithyroid drugs were considered contraindicated, the patient was treated with propranolol 40 mg tid, dexamethasone $4 \mathrm{mg} /$ day and cholestyramine $2 \mathrm{~g}$ four times a day (without further dose increase because of gastrointestinal intolerance).

The patient showed a favorable evolution, with notable decrease in hyperthyroid symptoms and normalization of T4 $(9.4 \mathrm{mcg} / \mathrm{dL})$ and $\mathrm{T} 3$ $(101.9 \mathrm{ng} / \mathrm{dL})$ after one week of treatment. He was discharged with prednisone $20 \mathrm{mg}$ /day and received $20 \mathrm{mCi}$ of radioactive iodine (RAI) six days afterwards. Periodic follow-up showed progressive decrease in bilirubin which allowed down-titration of prednisone until suspension after 3 months of treatment (Figure 1). Liver biopsy showed mild portal hepatitis with canalicular cholestasis, without signs of specificity. Considering the aforementioned result as well as the resolution of cholestasis after achieving euthyroidism, the diagnosis of hyperthyroidism-induced cholestasis was made.

Ten weeks after RAI the patient was euthyroid and had normal bilirubin concentration (Table 1). One year after RAI treatment the patient is euthyroid taking levothyroxine $150 \mathrm{mcg}$ daily and his liver function tests are normal (Table 1).

\section{Discussion}

Between 45 and $90 \%$ of hyperthyroid patients develop altered liver tests, usually mild ${ }^{1}$. The most usual being elevated alkaline phosphatases of bone and liver origin, followed by elevations in aminotransferases or GGT, and least commonly direct hyperbilirubinemia ${ }^{2,3}$. Acute, symptomatic cases are very uncommon, including hepatitis, cholestasis and fulminant hepatic failure ${ }^{2}$. The presence of a severe cholestatic pattern has been scarcely reported in the literature ${ }^{6}$. 
The physiopathological mechanisms involved in liver biochemical abnormalities are still unclear, with many proposed theories. The first hypothesis is the development of ischemia and tissue necrosis (mainly in centrilobular zone 3 ) secondary to an increase in liver oxygen consumption induced by thyrotoxicosis, without a concomitant increase in hepatic blood flow ${ }^{1}$. Findings in liver biopsies of hyperthyroid patients support this premise, including centrilobular necrosis, decreased number of ribosomes and mitochondrial density. Thyrotoxicosis-induced right heart failure with venous congestion is a second suggested mechanism, especially in severe cases $^{6}$, while a third hypothesis involves a direct hepatotoxic effect of excess thyroid hormones. Cellular lines in animal models have shown disruption of the outer mitochondrial membrane after exposure to high concentrations of T3, with consequent cytosolic liberation of cytochrome $\mathrm{C}$, followed by activation of caspases 3 and 9 and cellular apoptosis ${ }^{5}$. The relationship between thyroid hormone concentration and severity of liver disfunction in humans is controversial. Zhang et al. reported that the presence of $\mathrm{T} 4>5.8 \mathrm{ug} / \mathrm{dL}$ was a risk factor for development of liver test abnormalities, while $\mathrm{He}$ et al. found no such correlation ${ }^{3,5,7}$.

A fourth hypothesis involves the direct effect of TRAb. This assumption comes from studies which have correlated TRAb titers with a higher probability of developing liver abnormalities ${ }^{3,4,7}$.

The coexistence of other autoimmune liver disease is another factor to be considered, the most frequent being type 1 autoimmune hepatitis, which should be suspected in the presence of marked elevations in AST titers (usually $>5 \mathrm{xULN}$ ) and IgG, as well as positive antinuclear antibodies (ANA) and anti-smooth muscle antibodies (ASMA) ${ }^{8}$. The diagnosis is confirmed with characteristic biopsy findings such as interface hepatitis ${ }^{8}$. Primary biliary cirrhosis presents with a cholestatic pattern in liver function tests, usually accompanied by elevation in IgM titers and positive antimitochondrial antibodies (AMA). Far less frequent, primary sclerosing cholangitis can also present with a cholestatic pattern, without a characteristic immune marker ${ }^{8}$.

One last mechanism relating hyperthyroidism and liver involves antithyroid drugs (thionamides). Initial reports described a thionamide-specific pattern, with hepatocellular pattern in users of propylthiouracil (PTU) and a characteristic cholestatic pattern in users of thiamazole 9 . However, new studies such as the one by Wang and cols. showed that both drugs have a similar biochemical pattern, although with a higher incidence of hepatitis with thiamazole and liver failure with $\mathrm{PTU}^{10}$. The effect seems to be dose-dependent, mainly with $>15 \mathrm{mg} /$ day of thiamazole ${ }^{10}$.

We report a case of severe cholestasis in a patient with hyperthyroidism secondary to Graves' disease in whom cardiac insufficiency and other secondary causes were properly investigated. The delay in diagnosis can be explained by the lack of classic symptoms of hyperthyroidism at presentation, which developed acutely during hospital stay.

Liver biopsy showed unspecific findings. Sola and cols. described common findings in liver biopsies of five hyperthyroid patients: mild to moderate intrahepatic cholestasis and inflammatory lobular infiltrate with eosinophils and Kuppfer cell hyperplasia ${ }^{11}$.

The biopsy findings, as well as the presence of a marked elevation of direct bilirubin without concomitant increases in AP and GGT, suggest a canalicular cholestasis. This biochemical pattern is probably secondary to dysfunction in the canalicular efflux system of bile salts, bilirubin and organic anions ${ }^{12}$, usually associated to drugs. Relative hypoxia may be the driver mechanism of this canalicular defect in patients with hyperthyroidism ${ }^{13}$.

Regarding management, thionamides were withheld because of concerns they could aggravate liver function tests, although previous reports have used them with caution ${ }^{3}$. Other therapeutic alternatives in these case can include i) steroids, which reduce peripheral conversion of $\mathrm{T} 4$ to $\mathrm{T} 3$; ii) cholestyramine, a nonabsorbable resin that binds thyroid hormones in the intestine, preventing their enterohepatic recirculation; iii) high dose of inorganic iodine as lugol's solution or amiodarone, which inhibits its own organification in the thyrocyte, decreasing thyroid hormone synthesis; iv) propranolol, a betablocker which decreases peripheral conversion of $\mathrm{T} 4$ to $\mathrm{T} 3^{6,12}$. Our patient was treated with steroids (initially iv dexamethasone, followed by oral prednisone), cholestyramine and propranolol. We did not use an iodine load because of concerns regarding worsening of hyperthyroidism in the setting of a 
patient not exposed to antithyroid drugs, as well as to not hamper effectiveness of definite treatment with $\mathrm{RAI}^{14}$.

Bilirubin normalization was achieved ten weeks after administration of RAI. This clinical evolution was similar to previously reported cases, describing one to four months until normalization of liver function tests after resolution of hyperthyroidism.

In conclusion, we present the case of a patient with Graves' disease associated to a severe cholestatic pattern, with complete resolution after successful treatment of hyperthyroidism with RAI.

\section{References}

1. de Campos Mazo DF, de Vasconcelos GB, Pereira MA, de Mello ES, Bacchella T, Carrilho FJ, Cançado EL. Clinical spectrum and therapeutic approach to hepatocellular injury in patients with hyperthyroidism. Clin Exp Gastroenterol 2013; 6: 9-17.

2. Lin TY, Shekar AO, Li N, Yeh MW, Saab S, Wilson M, Leung AM. Incidence of abnormal liver biochemical tests in hyperthyroidism. Clin Endocrinol (Oxf) 2017; 86: 755-9.

3. Habershon S 1874 Exophthalmic goiter, heart disease, jaundice: death. Vol 1, The Lancet, 510-2.

4. Elias RM, Dean DS, Barsness GW. Hepatic dysfunction in hospitalized patients with acute thyrotoxicosis: a decade of experience. ISRN Endocrinol 2012: 325092.

5. Upadhyay G, Singh R, Kumar A, Kumar S, Kapoor A, Godbole MM. Severe hyperthyroidism induces mitochondria-mediated apoptosis in rat liver. Hepatology 2004; 39: 1120-30.

6. He K, Hu Y, Xu XH, Mao XM. Hepatic dysfunction related to thyrotropin receptor antibody in patients with Graves' disease. Exp Clin Endocrinol Diabetes 2014; 122: 368-72.

7. Yan LD, Thomas D, Schwartz M, Reich J, Steenkamp D. Rescue of Graves Thyrotoxicosis-Induced Cholestatic Liver Disease Without Antithyroid Drugs: A Case Report. J Endocr Soc 2017; 1: 231-6.

8. Zhang R, Tian X, Qin L, Wei X, Wang J, Shen J. Factors predicting abnormal liver function tests induced by Graves' disease alone: a retrospective cohort study. Medicine (Baltimore) 2015; 94: e839.

9. Carbone M, Neuberger JM. Autoimmune liver disease, autoimmunity and liver transplantation. J Hepatol 2014; 60: 210-23.

10. Heidari R, Niknahad H, Jamshidzadeh A, Abdoli N. Factors affecting drug-induced liver injury: antithyroid drugs as instances. Clin Mol Hepatol 2014; 20: 237-48.

11. Wang MT, Lee WJ, Huang TY, Chu CL, Hsieh CH. Antithyroid drug-related hepatotoxicity in hyperthyroidism patients: a population-based cohort study. Br J Clin Pharmacol 2014; 78: 619-29.

12. Sola J, Pardo-Mindán FJ, Zozaya J, Quiroga J, Sangro B, Prieto J. Liver changes in patients with hyperthyroidism. Liver 1991; 11: 193-7.

13. Ampuero J, García ES, Lorenzo MM, Calle R, Ferrero P, Gómez MR. Stanozolol-induced bland cholestasis. Gastroenterol Hepatol 2014; 37: 71-2.

14. Regelmann MO, Miloh T, Arnon R, Morotti R, Kerkar N, Rapaport R. Graves' disease presenting with severe cholestasis. Thyroid 2012; 22: 437-9.

15. Ross DS, Burch HB, Cooper DS, Greenlee MC, Laurberg P, Maia AL, Rivkees SA, Samuels M, Sosa JA, Stan MN, Walter MA. American Thyroid Association Guidelines for Diagnosis and Management of Hyperthyroidism and Other Causes of Thyrotoxicosis. Thyroid 2016; 26: 1343-421. 